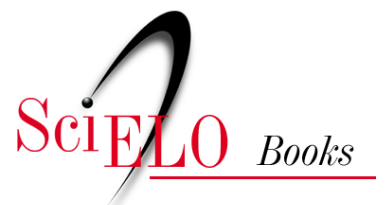

\title{
9 - Memória e identidade: escola família agrícola (EFA) de Serra do Mel/RN
}

\author{
Maria Rosivania Pereira Feitosa Duarte \\ Kyara Maria de Almeida Vieira
}

\section{SciELO Books / SciELO Livros / SciELO Libros}

DUARTE, M. R. P. F., VIEIRA, K. M. A. Memória e identidade: escola família agrícola (EFA) de Serra do Mel/RN. In: OLIVEIRA, G. M. C., and VIEIRA, K. M. A., eds. Patrimônio, povos do campo e memórias: diálogos com a cultura, a arte e a educação [online]. Mossoró: EdUFERSA, 2020, pp. 137-152. ISBN: 978-65-87108-09-4. https://doi.org/10.7476/9786587108605.0010.

\section{(c) (1)}

All the contents of this work, except where otherwise noted, is licensed under a Creative Commons Attribution 4.0 International license.

Todo o conteúdo deste trabalho, exceto quando houver ressalva, é publicado sob a licença Creative Commons Atribição 4.0. 


\title{
MEMÓRIA E IDENTIDADE: ESCOLA \\ FAMÍLIA AGRÍCOLA (EFA) DE \\ SERRA DO MEL/RN
}

\author{
Maria Rosivania Pereira Feitosa Duarte \\ Kyara Maria de Almeida Vieira
}

Este capítulo tem como tema central a história da Escola Família Agrícola de Serra do Mel (EFAMEL), contada a partir das memórias das pessoas que fizeram parte da escola: ex-estudantes, ex-professores (as) e o seu fundador. Assim, pretendemos problematizar essa experiência que se entrecruzou com os aspectos culturais, educacionais, sociais do município de Serra do Mel-RN, e também com a produção de identidades dos sujeitos.

Nossa pesquisa foi realizada a partir da história oral, com entrevistas ${ }^{29}$ semiestruturadas, por considerar a memória “(...) um elemento constituinte do sentimento de identidade, tanto individual quanto coletiva, na medida em que ela é também um fator extremamente importante do sentimento de continuidade e de coerência de uma pessoa ou de um grupo em sua reconstrução de si" (POLLAK, 1992, p. 204).

Segundo dados do IBGE, o município de Serra do Mel-RN nasceu de um projeto de colonização, idealizado na década de 1970 pelo então governador José Cortez Pereira de Araújo ${ }^{30}$. Este projeto foi executado conforme o

29 As entrevistas foram realizadas com quatro ex-estudantes, dois ex-professores e o fundador da referida escola. As mesmas foram transcritas tal qual a narrativa das pessoas que colaboraram com nossa pesquisa, sem correções gramaticais, com o intuito de preservar a originalidade das falas. Todas as pessoas entrevistadas assinaram o Termo de Consentimento Livre e Esclarecido, autorizando a gravação da entrevista e publicação de trechos de suas falas no presente trabalho.

30 José Cortez Pereira de Araújo governou o Rio Grande do Norte no período de 1970 a 1974 (LIMA, 2003, p. 5). 
modelo de Moshav ${ }^{31}$ em Israel, que era um tipo de comunidade rural cooperativa. A finalidade do projeto de Serra do Mel-RN era fazer uma reforma agrária na região, doando lotes produtivos para agricultores sem-terra, além de absorver o grande contingente de salineiros desempregados devido a mecanização do trabalho das salinas. Vale destacar que a região salineira do Rio Grande do Norte compreende os municípios de Areia Branca, Mossoró, Grossos, Galinhos, Guamaré e Macau. As "Agrovilas da Serra do Mel” (na época zona rural de Mossoró) foram alguns dos destinos dos milhares de trabalhadores desempregados pela mecanização da produção salineira potiguar (GALVÃO, 2016, p. 7).

Os lotes foram divididos em vilas comunitárias de produção, sendo 23 núcleos habitacionais (21 vilas rurais e 2 vilas centrais) que recebeu, cada vila, o nome de um Estado brasileiro. As agrovilas distam uma das outras cinco (5) quilômetros, dificultando o acesso às escolas, que na época só existiam na vila central. Neste contexto surgiu a EFAMEL que minimizou essas dificuldades de acesso à escola, já que funcionava em regime de semi-internato e os/as estudantes necessitariam se deslocarem de casa apenas uma vez por semana, cada quinze (15) dias.

A Escola Família Agrícola de Serra do Mel (EFAMEL) foi fundada em 1989, embora seu processo de planejamento e construção tenha iniciado em 1986. Foi construída para atender a uma necessidade educacional do referido município. Funcionou por pouco mais de uma década (19902001), atendendo adolescentes e jovens camponeses/as. Foi idealizada por um padre italiano, a quem chamaremos pelo pseudônimo de José32, que conhecia a experiência da Itália e do Estado do Espírito Santo e tinha como objetivo principal viabilizar a permanência dos/as adolescentes e jovens

31 São colônias baseadas no princípio da célula familiar e na propriedade privada (RODRIGUES, 1964, p. 85).

32 Padre salesiano, fundador da Escola Família Agrícola de Serra do Mel-EFAMEL. Chegou ao Brasil em 1978, para uma missão da Inspetoria de Verona- Itália. Tem 76 anos, residente no município de Areai Branca/RN. 
no município, pois no ensino tradicional eles tinham que se deslocar de sua comunidade para o centro urbano de Serra Mel, ou até mesmo cidades vizinhas, para ter acesso à educação.

Neste contexto surgiu a EFAMEL que minimizou essas dificuldades de acesso à escola, já que funcionava sob o regime da pedagogia da alternância, que segundo Teixeira; Bernartt e Trindade (2008, p. 227) é uma metodologia de ensino que vincula escola e comunidade a partir da aliança entre teoria e prática, ensino contextualizado e valorização do meio rural respeitando suas especificidades, aspectos esses concernentes à Educação do Campo. Segundo Molina e Freitas (2011, p. 19),

A Educação do Campo vincula-se à construção de um modelo de desenvolvimento rural que priorize os diversos sujeitos sociais do campo, isto é, que se contraponha ao modelo de desenvolvimento hegemônico que sempre privilegiou os interesses dos grandes proprietários de terra no Brasil, e também se vincula a um projeto maior de educação da classe trabalhadora, cujas bases se alicerçam na necessidade da construção de um outro projeto de sociedade e de Nação (MOLINA; FREITAS, 2011, p. 19).

Neste sentido, a EFAMEL foi pensada de modo a atender as necessidades da sua logística de funcionamento, que deveria comportar os/as estudantes. Seu projeto foi elaborado a fim de permitir o ensino prático das atividades agrícolas, desenvolvidas por eles/as mesmos/as. O trabalho de organização e manutenção do espaço da Escola também era feito pelos próprios/as educandos/as, os/as eram divididos em equipes de acordo com as tarefas.

A EFAMEL ofertava o ensino de $5^{\mathrm{a}}$ a $8^{\mathrm{a}}$ série (que corresponde do $6^{\circ}$ ao $9^{\circ}$ ano atual $)^{33}$. Seu ensino era organizado de acordo com a Pedagogia da Alternância, uma metodologia que compreende o ensino como dividido em tempo escola (período em que os estudantes estão na escola, construindo conhecimento) e tempo comunidade (período em que os estudantes estão na

33 Após sanção da Lei no 11.274, de 06 de fevereiro de 2006, que estabelece as diretrizes e bases da educação nacional, dispondo sobre a duração de 9 anos para o ensino fundamental, com matrícula obrigatória a partir dos 6 anos de idade (disponível em: www.planalto.gov.br). 
comunidade praticando o que aprenderam). No tempo escola, os estudantes tinham dois turnos de aula, o matutino e o vespertino, para compensar os quinze dias que ficariam em casa (tempo comunidade).

Esta escola buscou proporcionar aos seus estudantes a oportunidade de despertar o interesse pelas atividades agrícolas, as quais suas famílias já praticavam, a fim de buscar uma profissionalização que contribuiria para sua permanência no campo, através da aliança entre teoria e prática e valorização do meio rural.

A Pedagogia da Alternância é definida por Teixeira; Bernartt e Trindade (2008, p. 227, p. 229) como uma pedagogia que "consiste numa metodologia de organização do ensino escolar que conjuga diferentes experiências formativas distribuídas ao longo de tempos e espaços distintos, tendo como finalidade uma formação profissional". A EFAMEL buscava sempre considerar o meio em qual os/as educandos/as estavam inseridos/as, aliando suas próprias experiências com o saber científico e sistematizado partilhado na escola.

Após breve apresentação da EFAMEL, adentraremos na discussão sobre construto da identidade a partir das vivências individuais e coletivas, tendo como referência as memórias dos sujeitos, posto que "[...] a construção da identidade é um fenômeno que se produz em referência aos outros, em referência aos critérios de aceitabilidade, de admissibilidade, de credibilidade, e que se faz por meio da negociação direta com outros" (POLLAK, 1992, p. 204).

Ainda sobre identidade, com base nas proposituras de Hall (2005), podemos afirmar que a identidade se forma com o tempo, através de processos variados, ou seja, não é algo que trazemos conosco quando nascemos. Dessa forma, a construção da identidade dos sujeitos que compunham a Escola Família Agrícola de Serra do Mel - EFAMEL, também se deu num tempo e num espaço, através das experiências individuais e coletivas, articuladas pelo projeto pedagógico da mesma.

Considerando os objetivos pedagógicos da EFAMEL, que eram: i) ensino contextualizado; ii) conexão de teoria e prática; iii) incentivo à permanência dos/das jovens no campo; iv) convivência familiar, é possível inferir que esses objetivos contribuíram de alguma forma para a formação da identidade 
campesina dos/das estudantes que fizeram parte dessa singular experiência educativa. Segundo Maheirie (2002, p. 35): “O Eu, ou a identidade, ou a especificidade do sujeito, aparece como produto das relações do corpo e da consciência com o mundo, consequência da relação dialética entre objetividade e subjetividade no contexto social". Ainda dialogando com a autora, esta define identidade como sendo características próprias de cada indivíduo produzida a partir das relações sociais:

A constituição da identidade tem a marca da ambiguidade, da síntese inacabada de contrários, daquilo que é individual e coletivo, daquilo que é próprio e alheio, daquilo que é igual e diferente, sendo semelhante a uma linha que aponta ora para um polo, ora para outro. A utilização do conceito de identidade nos permite desvelar os indivíduos, grupos, ou coletividades, localizá-los no tempo e no espaço, "identificando-os" como estes e não outros, mesmo em metamorfose (MAHEIRIE, 2002, p. 41).

Desta forma, a identidade não é algo puramente individual e que, embora seja uma especificidade do sujeito, também é coletiva por ser construída pela relação com o outro, em um determinado espaço e em um tempo específico, e por isso mesmo essa identidade está em constante mudança. Partindo, pois, da ideia de que o sujeito é visto como subjetividade objetivada (MAHEIRIE, 2002), trataremos de destacar também o conceito de subjetividade, acentuado pela mesma autora: "[...] A subjetividade é compreendida como uma dimensão do sujeito, assim com objetividade que, relacionadas dialeticamente no contexto social, produzem o sujeito" (MAHEIRIE, 2002, p. 37). Assim, a partir da relação com o conjunto social, em um determinado espaço e em um determinado tempo, é que se constrói o sujeito.

Nesse mesmo sentido se faz importante e necessário pensar em identificação, conceito que sugere que os indivíduos mais estão alguma coisa, do que são alguma coisa, considerando que a identificação é algo mutável, inconstante. A esse respeito Oliveira (2003, p. 119) afirma:

A noção de identidade contém duas dimensões: a pessoal (ou individual) e a social (ou coletiva). (...) Nessa linha de raciocínio a identidade social surge como a atualização do processo de identificação e envolve 
a noção de grupo, particularmente a de grupo social. Porém, a identidade social não se descarta da identidade pessoal, pois esta também de algum modo é um reflexo daquela (OLIVEIRA, 2003, p. 119).

No que se refere aos sujeitos desta pesquisa (ex-alunos (as), ex-professores (as) e ex-funcionários da EFAMEL), o contexto social em que estavam inseridos era, sobretudo, o campo, este que, enquanto espaço geográfico, é o lugar de vida, onde as pessoas realizam suas atividades cotidianas e adquirem sua identidade cultural campesina (FERNANDES, 2011). Além disso, o regime de semi-internato, utilizado na Pedagogia da Alternância, proporcionou aos sujeitos desse processo um intenso convívio, o qual se fez possível a identificação em relação ao outro, seja por afinidades, seja por (in) compatibilidade de ideias, sentimentos e gostos. Sendo assim, como aponta Oliveira (2003), a identidade social é uma intersecção da identidade individual, uma se constrói em relação a outra, a partir dos comportamentos e das linguagens sociais.

Para fundamentar a discussão sobre o construto de identidade, é imprescindível também inferir a questão da linguagem esta que Vieira (2006, p. 23) define como:

Algo que não é neutro, mas que é partir dela que alguns discursos são tomados como verdade e se colocam na episteme das sociedades, no 'verdadeiro'; é a partir da linguagem que atribuímos significados ao mundo e estabelecemos quais desses significados são genuínos ou não (VIEIRA, 2006, p. 23).

É através da linguagem que nos identificamos como sujeitos que somos, nos afirmamos e negamo-nos, sempre em relação ao outro. Daí a necessidade das relações sociais para construirmos nossas identidades, embora reconhecendo que seja passível de modificação. A linguagem social nos permite tomar posições, ter opiniões e atribuir significados, seja de afirmação ou de negação do discurso; e assim tecemos nossa identidade, ou seja, com o que, ou como, nós nos identificamos. Nesse sentido, a EFAMEL teve importante papel na construção dessas relações que fundamentam as identidades das pessoas que participaram de nossa pesquisa. 
Para entender os aspectos de identificação dos sujeitos lançamos mão dos relatos das de ex-estudantes da EFAMEL, percebendo a importância da memória coletiva e individual para rememorar acontecimentos vividos, pois, de acordo com Bosi (1993, p. 280-281) “[...] a lembrança pura traz à tona da consciência um momento único, singular, irreversível, da vida [...] a memória é sim um trabalho sobre o tempo, mas sobre o tempo vivido, conotado pela cultura e pelo indivíduo". Sendo assim, segue relato de uma estudante:

Bem, é, o convívio lá com os meus colegas era como família, irmãos, irmandade, na unidade, né? É uma questão em que a gente sabia dividir as coisas um para com o outro, né? E tinha essa questão de preocupação quando os outros tinham saudade de casa, né? Porque a gente passava quinze dias, né? Lá. E tinha com certeza aquela grande saudade, né? Do seio familiar. Mas a convivência fazia com que ali, é, suprisse essa questão da, dessa falta do seio familiar e se tornava uma nova família, né? E com os professores era aquela coisa muito harmônica, graças a Deus, eles eram bastantemente (sic) assim, era, contribuíam muito, né? Para o nosso crescimento, a preocupação conosco, né? E realmente foi uma coisa bastantemente (sic) assim, bem favorável, para todos aqueles que passaram por esta, é, grande vivência familiar (ANE, 2017) ${ }^{34}$.

A fala da ex-estudante Ane aponta que suas lembranças não são apenas individuais, incluem também outros sujeitos e a analogia que ela faz com o passado se dá em relação às outras pessoas, enfatizando o convívio familiar experienciado nessa Escola, o que confirma que o construto da identidade envolve o outro, pois nos posicionamos em oposição ou por afinidade a alguém.

A experiência promovida a partir da Pedagogia da Alternância e do regime de semi-internato incluía o desafio de lidar a intensa convivência entre pessoas advindas de realidades/ educação doméstica distintas, com

34 Ex-estudante da EFAMEL, no período de 1995 a 1998, entrevistada em 19 de outubro de 2017, pela pesquisadora Maria Rosivania Pereira Feitosa Duarte, da qual foi preservada sua identidade, sendo usado um pseudônimo. Reside no município de Serra do Mel, 42 anos, graduada em Pedagogia. 
a saudade e falta da família primária, mas também favorecia a construção de laços que iam além da transmissão/ produção de conhecimento, ensino e aprendizagem de conteúdo, avaliações e cumprimento da carga horária.

Sobre isso a ex-professora Maria $(2018)^{35}$ relata:

Eu acho também que apesar das dificuldades a gente criou aquele laço de amizade, uma afetividade, porque eu me sentia mãe de todos, sabe? (risos) Era um exagero, mas era verdade, eu me sentia mãe, a gente cuidava muito, a gente tinha muito cuidado, a gente tinha medo de acontecer alguma coisa, é, se adoecesse, se, alguma coisa, a gente se envolveu tanto que tinha finais de semana que eles diziam assim: "Não, não quero ir pra casa, deixe eu ficar aqui?" E eu dizia: "fique”.

Os laços de amizades relatados pela professora são ligações que transcendem o espaço físico da Escola e o tempo vivido nela, pois percebemos na fala de alguns/algumas estudantes que entre os principais legados dessa Escola estão as amizades construídas e perpetuadas ao longo do tempo.

As ideias expostas acima nos permitem ainda afirmar que as memórias são fragmentos de um passado vivido e experienciado particular e coletivamente, que permite a reconstrução da história individual e também coletiva. Essa reconstrução se faz presente nas falas dos principais sujeitos envolvidos nessa pesquisa, onde sempre fazem relação ao passado, e as experiências e vivências individuais e coletivas, pois como afirma Maheirie (2002) é a partir das relações vividas que a subjetividade constrói as experiências afetivas e reflexivas, produzindo assim significados singulares e coletivos para os sujeitos.

Ou ainda como afirma Oliveira (2003, p. 119):

A noção de identidade contém duas dimensões: a pessoal (ou individual) e a social (ou coletiva). (...) Nessa linha de raciocínio a identidade social surge como a atualização do processo de identificação e envolve

35 Ex-professora da EFAMEL em entrevista realizada em 02 de agosto de 2018, pela pesquisadora Maria Rosivania Pereira Feitosa Duarte, da qual foi preservada sua identidade, usando um pseudônimo. Reside no município de Mossoró-RN, 66 anos, graduada em Pedagogia. 
a noção de grupo, particularmente a de grupo social. Porém, a identidade social não se descarta da identidade pessoal, pois esta também de algum modo é um reflexo daquela (OLIVEIRA, 2003, p. 119).

A convivência diária e constante permitia identificação com a EFAMEL enquanto espaço familiar e de pertencimento. Não ir para casa da família nos fins de semana permitidos poderia ter muitos motivos. Mas, também indica que a escola se tornara um espaço também familiar e de identificação.

Indagado sobre as experiências vividas na EFAMEL o ex-estudante Francisco ${ }^{36}$, narrou:

A contribuição foi muita, foi muita, eu sou o que sou hoje, graças a contribuição que a EFAMEL, né? A Escola me deu, né? Porque assim, eu, eu enquanto aluno daquela Escola, eu aprendi muitas coisas, né? Na questão de trabalhar socialmente, né? Na questão de trabalhar em grupo, né? Na Escola. Aprendi na Escola que a gente trabalhava todo mundo junto, né? E isso aí levou, me trouxe, até o dia de hoje, porque a gente vê que é o que nós temos é, de experiência daquela Escola, do que é que passou na Escola Agrícola foi muito, foi experiência muito boa, foi experiência de que pra trazer pra vivência do que a gente vive hoje, no município (FRANCISCO, 2018).

O estudante destaca que o aprendizado na EFAMEL ultrapassou a perspectiva utilitária e imediata do conhecimento, pois conseguiu levar pela vida, porquanto, o mesmo desenvolve trabalhos em grupo em sua comunidade, que rompe e borra a lógica individualista capitalista, que tende a mercantilizar as relações. A EFAMEL não lhe possibilitou apenas os conhecimentos práticos para seu desempenho profissional, mas também, uma experiência de vida que mais tarde auxiliariam na sua atuação social e cidadã, no que diz respeito ao engajamento em trabalhos comunitários.

Para outros sujeitos a contribuição por parte dessa Escola pode ser percebida de outras formas, como aponta a fala do estudante a seguir:

36 Ex-estudante da EFAMEL, no período de 1991 a 1993, em entrevista concedida em 25 de maio de 2018, à pesquisadora Maria Rosivania Pereira Feitosa Duarte, do qual foi preservada a identidade, sendo usado um pseudônimo. Residente do município de Serra do Mel/RN, 43 anos, Ensino Médio Completo. 
Primeiro falando da questão profissional, é, dentro da agricultura, deu uma base muito boa, porque a gente tínhamos (sic) duas matérias específicas, né? Como a Zootecnia, né? E a Agricultura. Então a gente aprendeu bastante coisa, como, como o manejo do cajueiro, o manejo da terra, a criação de ovelha, né? (...) Como cidadão, essa foi extremamente importante, até mesmo porque a fase mais difícil da vida do ser humano, acredito eu que seja na adolescência, né? Entrei, eu entrei com treze anos, de doze pra treze anos, e sai com dezessete. É a fase mais complicada, mais difícil essa adolescência, então ela deu uma formação bacana, muito boa, porque ela fortalecia as amizades, a responsabilidade. (...) Fora a questão do cooperativismo, ser companheiro com os colegas, quando um adoecia, tinha um problema, a gente tá sempre perto, sempre conversando, isso foi de grande importância $\left(\right.$ TIAGO, 2018) ${ }^{37}$.

Esse estudante aponta como contribuições para sua vida profissional e também para sua vida pessoal, os laços de amizades cultivados através da convivência intensa e enfatiza também a questão do fortalecimento do senso de responsabilidade. São elementos que compõem sua identidade e que foram possíveis de serem vividos a partir da metodologia da Pedagogia da Alternância que, segundo Reis e Hage (2011, p. 120), promove uma formação que

[...] inclui e transcende o espaço escolar, e, portanto, a experiência torna-se um lugar com estatuto de aprendizagem e produção de saberes em que o sujeito assume seu papel de ator protagonista, apropriando-se individual e coletivamente do seu processo de formação (REIS; HAGE, 2011, p. 120).

Estudantes que tem a experiência educacional a partir da Pedagogia da Alternância são responsáveis pela sua formação, no sentido de, a partir das suas experiências individuais e coletivas, produzirem seu próprio

37 Ex-estudante da EFAMEL, no período de 1996 a 1999, entrevistado em 08 de maio de 2018, pela pesquisadora Maria Rosivania Pereira Feitosa Duarte, do qual foi preservada sua identidade, sendo usado um pseudônimo. Residente do município de Serra do Mel/RN, 37 anos, Ensino Médio Completo. 
conhecimento, na esfera escolar e comunitária. No que se refere ao modelo peculiar da EFAMEL, o ensino se dava de forma contextualizada com a realidade de seus estudantes. Segundo o fundador da referida escola:

[...] o modelo Escola Família Agrícola é um modelo que deveria centralizar todas as disciplinas ao redor da experiência dos alunos com seus pais. Então, a Matemática teria que ajudar a fazer todos os cálculos e etc., que os pais têm que fazer, um financiamento no banco, uma coisa assim, é num empréstimo, numa compra e tudo mais, tá? A Geografia, teria que ser uma Geografia que ajuda a entender a sua terra afinal, no mundo, essa terra que tem essas características. A História deveria conseguir entender a situação do povo trabalhador, agricultor. Claro, estuda tudo que se estuda em outros cantos, e até melhor, com o incentivo a pesquisar (VENTURELLI, 2018).

Para tal objetivo a Escola dispunha em sua grade curricular de componentes curriculares como Agricultura e Zootecnia, estas que auxiliariam no cotidiano dos/das estudantes, compreendendo que os/as mesmos/as, em sua maioria, eram filhos/as de agricultores/as, que tinham o cultivo da terra e o cuidado de animais como suas principais atividades laborais. Além disso, o ensino dos outros componentes, segundo Venturelli (2008), respondia as necessidades do cotidiano e espaço dos/as estudantes.

Ainda sobre contribuição pessoal, a estudante Lana ${ }^{38}$ afirmou:

[...] Eu voltei de lá outra pessoa, lá era uma escola família, né? Família Agrícola de Serra do Mel e a gente era muito bem trabalhado quanto a isso lá na Escola, era uma família mesmo. Eu agradeço hoje, assim parte do que eu sou, ao que aprendi e vivi lá na Escola. [...] Contribuiu, porque eu era assim meio rebelde, era muito é, individualista. Lá não, eu vi que era diferente, você tinha que fazer sua parte, colaborar com o colega, é, não tinha que ser egoísta, eu sei que mudou muita coisa (LANA, 2018).

38 Ex-estudante da EFAMEL, no período de 1990 a 1993, entrevistada em 19 de abril de 2018, pela pesquisadora Maria Rosivania Pereira Feitosa Duarte, da qual foi preservada sua identidade, sendo usado um pseudônimo. Reside da Serra do Mel, 46 anos, graduada em Pedagogia. 
Para essa estudante, a EFAMEL contribuiu de forma a fazê-la se reconhecer como egoísta, e a modificar suas ações por meio das regras e normas de convivência, já que na referida escola tudo era partilhado e as tarefas feitas de modo coletivo. Sendo assim, reconhecendo um elemento da sua identidade que se mostrou na relação com o outro, e que foi possível modificar, pois como diz Maheirie (2002), a identidade é mutável, ou seja, passível de mudança de acordo com o tempo, espaço e da relação com o outro.

\section{Considerações Finais}

Em análise dos relatos das experiências vividas nessa Escola pelos/as estudantes entrevistados/as, podemos perceber que cada sujeito identificou contribuições diferentes para formação pessoal e profissional. Embora todos/as tenham vivenciado a mesma metodologia, cada um/a atribuiu significados diferentes para as experiências vividas. Indagados/as sobre as contribuições desse Escola para suas vidas, enfatizaram aspectos variados: convívio familiar, trabalho coletivo, ensino contextualizado.

Podemos afirmar que a memória é um fenômeno social e individual e que existe uma ligação estreita entre memória e identidade. Como afirma de Pollak (1992, p. 204):

(...) Aqui o sentimento de identidade está sendo tomado no seu sentido mais superficial, mas que nos basta no momento, que é o sentido de si, para si e para os outros. Isto é, a imagem que uma pessoa adquiri ao longo da vida referente a ela própria, a imagem que ela constrói e apresenta aos outros e a si própria, para acreditar na sua própria representação, mas também para ser percebida da maneira como quer ser percebida pelos os outros (POLLAK, 1992, p. 204).

A identidade se constrói com base no sentido que empregamos a nós mesmos, e para os outros, a partir da memória do vivido, sempre tomando como base o outro, as afinidades, as diferenças e as relações sociais.

Assim, após considerar as análises expostas neste texto, a partir do aporte teórico e das falas dos sujeitos entrevistados, é possível afirmar que a EFAMEL tem forte relação com a construção da identidade das pessoas que vivenciaram sua prática pedagógica. Pautando-se na Pedagogia da 
Alternância e no semi-internato, a vivência na EFAMEL contribuiu de forma singular e autêntica para formação pessoal e profissional dos sujeitos envolvidos com a Escola.

A contribuição para formação dos/das estudantes no aspecto pessoal vai desde a produção do senso de responsabilidade, no respeito às pessoas e suas diferenças, no que se refere as diferenças de etnia, religião, a também a aprende a viver no coletivo, dividindo, compartilhando. Quanto ao aspecto profissional, a EFAMEL permitiu que os/as estudantes aprendessem a valorizar seu espaço de vivência, o campo, enxergando que é possível e viável viver bem no campo, produzindo e tecendo relações e saberes. Desta feita a EFAMEL realizou seu papel enquanto escola do campo, se considerarmos que

A identidade da escola do campo é definida pela sua vinculação às questões inerentes à sua realidade, ancorando-se na temporalidade e saberes próprios dos estudantes, na memória coletiva que sinaliza futuros, na rede de ciência e tecnologia disponível na sociedade e nos movimentos sociais em defesa de projetos que associem as soluções exigidas por essas questões à qualidade social da vida coletiva no país (CNE/CEB 1, art. 2, 2002).

A partir das proposições teóricas apresentadas e defendidas no percurso desse capítulo, constatamos que a identidade se constrói em um determinado tempo, em um determinado espaço, e também se faz em relação ao outro; a identidade pessoal se constrói a partir do contexto a qual esteja inserido, ou seja, a forma como os/as estudantes da EFAMEL se identificam em seus discursos, diz um pouco sobre o conjunto social a qual os/ as mesmos/as estavam ou estão inseridos/as.

As identidades formam-se com o passar do tempo, a partir de múltiplos processos (HALL, 2005). Considerando isso, a experiência na EFAMEL compõe um fragmento de tempo vivido das pessoas que dela participaram; um fragmento significativo no que diz respeito às ressonâncias deixadas para vida de cada um, de cada uma. Assim, a nossa pesquisa permite afirmar que a EFAMEL conseguiu cumprir em grande medida, com o objetivo a que se propunha de formar cidadãos que valorizassem o meio rural, que conseguissem respeitar as outras pessoas, que aprendessem a partilhar 
objetos, sentimentos, conhecimentos. Neste sentido, podemos afirmar que a EFAMEL, em seus mais variados aspectos, contribuiu de modo ímpar para a construção dos sujeitos que participaram de sua existência, assim como para formação da identidade campesina dos/as ex-estudantes que participaram desse modelo pedagógico. 


\section{REFERÊNCIAS}

BOSI, E. Memória e sociedade: lembrança de velhos. 3. ed. São Paulo: Companhia das Letras, 1993. p. 277-284.

BRASIL. Ministério da Educação. Resolução CNE/CEB 1, de 3 de abril de 2002. Institui Diretrizes Operacionais para a Educação Básica nas Escolas do Campo. Diário Oficial da União, Brasília, DF, 20 dez. 1996. Disponível em: https://bit.ly/3miBJ7H. Acesso em: 14 set. 2020. FERNANDES, B. M. Diretrizes de uma Caminhada. In: FERNANDES, B. M. Por uma educação do campo. 5. ed. Petrópolis, RJ: Vozes, 2011. p. 134-145.

GALVÃO, I. R. A Reconfiguração produtiva do circuito espacial de produção salineiro e as transformações no espaço produtivo de Macau/RN. 2016. 312 f. Tese (Doutorado em Geografia) - Universidade Estadual do Ceará, Fortaleza, 2016.

HALL, S. A Identidade cultural da pós-modernidade. 10. ed. Rio de Janeiro: DP\&A, 2005. p. 7-48.

LIMA, L. P. Serra do Mel, um projeto de "vidas": o impacto do projeto de colonização planejada da Serra do Mel no cotidiano das famílias assentadas. 2003. 54 f. Monografia (Graduação em História) Universidade Federal do Rio Grande do Norte, Natal, 2003.

MAHEIRIE, K. Constituição do sujeito, subjetividade e identidade.

Interações, v. 7, n. 13, p. 31-44, jan./jun. 2002. 
MOLINA, M. C. Avanços e Desafios na construção da Educação do Campo. Em aberto, v. 24, n. 85, p. 17-31, abr. 2011.

OLIVEIRA, R. C. Identidade, étnica, identificação e manipulação.

Sociedade e Cultura, v. 6, n. 2, p. 117-131, jul./dez. 2003.

POLLAK, M. Memória e identidade social. Estudos Históricos, v. 5, n. 10, p. 200-212, 1992.

RODRIGUES, R. C. Formas de cooperativismo rural em Israel. Revista de Informação Legislativa, mar. 1964.

VIEIRA, K. M. A. A única coisa que nos une é o desejo: produção de si e sujeitos do desejo na vivência do homossexualismo em Campina Grande/PB. 2006. 182 f. Dissertação (Mestrado em Ciências Sociais) Universidade Federal de Campina Grande, Campina Grande, 2006. 